the centre, and, at times, the stricture is on one side. The middle of a long stricture is sometimes larger in diameter than at the ends, and frequently the urethra assumes a tortuous direction; or a membrane, denominated a bar, will extend across the canal. All these remarks on the variety of strictures,-which require different modes of treatment,by bougies, catheters, natron exsiccatum, argenti nitras, kali purum, and unguentum hydrargyri fortis, are introduced, in order to show the enormous amount of irritation which would be produeed in an already excited state of the urinary organs, where extraneous deposits are of too stimulating a nature to require any addition of inflammatory excitement to remove the cause. With a view of mitigating the existing symptoms by the removal of all unnatural secretions, and relaxing spasmodically contracted canals and passages, the soothing effects of heat and moisture are employed, as being well-known agents for the purpose. Nothing but an easy and perfectly controllable method of administering them is wanted, a desideratum which I have found attained by means of the instrument referred to, a diagram of which may in some measure serve to point out its construction and mode of application.

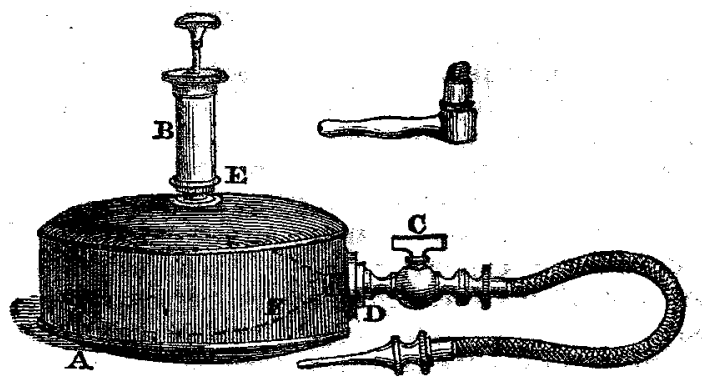

$A_{3}$ is a vessel made sufficiently strong, and of material impervious to air in a condensed state; $B$, a syringe for compressing atmospheric air into the said vessel; $\mathbf{C}$, is a stopcock which screws into the opening at $D$, and, in conjunction with the valve, E, serves to secure the injection, after being poured into the vessel through the opening, and to regulate the stream by diminishing or increasing the power from one drachm to the weight of several pounds; $G$, is one of the vessels for containing compressed air, or any of the gases. When the injector is to be used, unscrew the stopcock, $C$, and fill the vessel quite full of the liquid to be injected, then return the stopcock into the opening tolerably tight. The air-syringe, $\mathbf{B}$, must now be screwed into $\mathbf{E}$, which, being worked to the extent of twenty or thirty strokes, renders it ready for use. On introducing the ivory pipe in the usual way, the injection can be administered with any required degree of force, and in any position of the body, without the aid of a second person, and without the introduction of the slightest particle of atmospheric air.

Carlisle-street, Soho, 1849.

\section{A REPORT OF TWO CASES OF OSSIFICATION OF THE PLACENTA.}

Bx JAMES ROBERTSON, M.D., F.R.C.S., SURGEON TO THE HITCHIN INFIRMARY.

OTro says, that " even the dead child, with its membranes, if it have been retained for a long time in the mother's womb," is sometimes ossified; but I suppose this, or even the ossification of a part, as the placenta, is rare, for $I$ am not able to find any case recorded of late. Even Rokitansky omits to mention ossification amongst his "Abnormities of the Ovum," and appears not to have seen ossification of the placenta; for he says, "Foreign observers have given instances of osseous deposits in, or ossification of, the placenta; they are gibbous, nodulated, or cordate formations, which are probably developed in the placental tissue after it has been obliterated by inflammation, or in the fibrinous coagula caused by hæmorrbage."

As the instances are few, I have noted the two following, which have occurred in my practice:-

Mrs. - the mother of several children, supposed herself pregnant; but when about six months gone, her abdomen diminished in size, and she knew no more about it till about nine months afterwards, when suddenly, early one morning, she thought herself in labour, and quickly gave birth to a withered, leather-like fotus and placenta, of average size for a full-grown child, but which was entirely composed of an aggregation of spiculæ of bone. There was scarcely any discharge. The foetus was probably six months old, and had been retained in the womb nine months after its death.

Mrs. - supposed herself about five months gone with child, when the abdomen began to lessen in size. She consulted me about two months after this, when a tumour, having all the appearance, on examination, of the pregnant womb, was evident. Three months after she suddenly aborted a withered, leather-like fœetus, and a placenta which was bloodless, gristly, and had numerous spiculæe and plates of bone scattered over both free and attached surfaces. There was considerable flooding. The fotus was probably about five months old, and had been retained in the womb five months after its death.

Hitchin, Herts, August, 1849.

ON THE

\section{NEGLECTED AND UNHEALTHY CONDITION OF}

\section{A PART OF PADDINGTON.}

INEFFIOIENCY OF THE BOARD OF HEALTH, AND INGRATITCDE TOWARDS THE MEDICAL PROFESSION.

By JOHN GRAY, Esq, Surgeon, Londori.

Osserviva that an inquest was lately held on the body of a man who died of cholera in the Wharf-road, Paddington, and as you invariably expose the neglect of sanitary measures by the accredited authorities, I trust you will afford a niche in your paper for this letter, whereby the public may be made aware of the neglected and disgraceful state in which that locality is left by the parish authorities, and the utter inefficiency of the so-called board of health. I have frequent occasion to visit the neighbourhood where the attacked person died, and never could it be believed, except by actual inspection, that such a mass of filth could be allowed to accumulate and rot amidst a densely crowded population. Why, Sir, there is a dust-heap of garbage, of the most disgusting description, that has been lying for years, consisting of many thousand tons, with herds of swine luxuriating on this decomposed offal; the smell is so abominable, that the highly respectable inhabitants of Eastbourne-terrace, several hundreds of yards distant from it, and opposite, are obliged to keep their windows shut when the wind blows from that quarter. Besides, a vast amount of dung is allowed to be brought there by the Grand Junction Canal Company; and when it is turned over to be rotted for conveyance, the stench is so abominable that every one in the neighbourhood is instantly forced to close every aperture to shut out the horrid effluvium. If the ancient Egyptians were risited with plagues, surely the inhabitants of Dudley-grove have as much reason to complain as they had, for of all the places that ever I saw, this certainly is the place for the plague of flies, and such flies as are nowhere to be seen but there-they are not the ordinary flies, but great long fellows, with snouts like elephants, and stings in their tails as long as stocking needles. If $I$ said they swarmed in myriads $I$ should be infinitely behind the mark they are myriads and tens of myriads; and to preserve a piece of meat beyond a day is out of the question, for the bluebottle flies keep up a perpetual buzz, and hum around your ears as if a whole congregation of Welch ranters were catechising. Another and very serious matter for reflection is that of the Paddington churchyard, which is so filled with dead that it has actually risen upwards of four feet above the footpath with the remnants of mortality; but so long as the clergy, who have fees from the living and the dead, are allowed to bury there, so long will the danger to the living be permitted. Frequently as I pass through the churchyard when graves are being dug, the effluvium is disgustingly perceptible. What, $I$ ask, is the value of the sanitary board, when they allow such abominations? What is the use of Mr. Edwin Chadwick's statisties to society, by detailing the number of deaths, if no stop is put to the cause of them? Where is the pretended philanthropy of Dr. Southwood Smith, if he merely prates, and does not act? In short, I believe Mr. Edwin Chadwick has sucked the brains of the credulous and easily led medical profession for his own advantage; and Dr. Southwood Smith, after trying many dodges-viz., sanatoriums, \&c., has not been slack in bayoneting him in the rear. And then, in reference to that excellent and open-hearted good nobleman, Lord Carlisle, full of tenderness, and plastic in disposition, he would do much if greater firmness were characteristic of his mind.

No real rectification of malarious influenees can or ever will be achieved, until persons are appointed by authority to 
remove all nuisances; and who, I ask, are so fitted as those of the medical profession?-and for why? because they are in the hourly and daily habits of visiting the lowest and densest hamits of the poor and needy. But it seems the design of the government invariably to humiliate the medical profession, and make them subservient; and for what reason? why, because the profession has forgatten and neglected its value and position in society-it has been the tool and adjutor of corrupt ministration-it has not shown its strength and influence in political affairs-it has no recognised status as a body, like the church and the law, who are eternally in the front rank of beseechers for their own advantage. If the medical profession were true to themselves, and endeavoured to place a few more like Mr. Wakley in parliament, they then would have that just and proper weight which becomes their value and importance in the political community. I need not to apprise your mind of the many obligations the public owe to the profession for advantages they already possess. To us alone any progress in cleansing is due-not one syllable has emanated from the clergy or law to advance sanitary measures; to us belong the honour, to us the merit is denied. We are the fools by which the cunning weave their webs to procure to themselves warm comforts and independence.

Howley-place, Harrow-road, August, 1849.

\section{THE POISONED FLOUR AT STOURBRIDGE.}

REMARXS ON CASES OF POISONING BY THE ACETATE OF LEAD; AND ON DR. AYRE'S TREATMENT OF ASTATIC CHOLERA.

BY WILIIAM NORRIS, M.D.,

LATE FHYSICIAN TO THE STOURBRIDGE DISPENSARY.

Actre and chronic diseases of the abdominal viscera form a large class of the most violent and dangerous character that come under the treatment of the medical practitioner; and without early and deeisive measures they too often terminate fatally; and any opportunity that may occur to throw the least additional light on their pathology or treatment should be zealously cultivated.

As an awful occurrence has taken place in the towns of Stourbridge and Kidderminster, and the neighbouring villages, from the mistake of a miller's servant, who mixed about thirty pounds of acetate of lead, in the place of alum, with seventy or eighty sacks of flour, nearly a thousand persons having suf. fered from its poisonous effects, I shall make a feeble attempt to place before the profession anything new or striking, with the hope that it may induce eminent toxicologists to inves. tigate the alarming disease more minutely. The sufferings of the patients, in consequence of eating the poisoned bread, have been unusually severe, and protracted for some weeks after the violent symptoms first commenced; the strongest and most robust men (from long suffering, and from the frequent occurrence of violent paroxysms) have been reduced to the most emaciated and feeble state.

The persons who ate the bread, after a few weelss, complained of a peculiar taste; some compared it to soda, others to rusty needles, or copper. The tongue was covered with a darkish, cream-coloured mucus, and was soft and flabby; the gums were swollen, with a blue line on the margin, and in many cases the blue tinge extended nearly over the gums, and occasionally on the inner side of the lower lip, and in a faint degree over the mucous membrane of the mouth, and towards the fauces. The tonsils were in some cases enlarged, producing soreness of the throat; and in other cases there was salivation, a clear fluid flowing from the mouth many days after convalescence.

These symptoms were accompanied by loss of appetite, nausea, vomiting, flatulency, and obstinate constipation, with a sense of constriction in the throat and epigastrium, and a violent spasmodic pain and twisting around the umbilicus, which was retracted. The pain was sometimes increased by pressure, occasionally extending over the abdomen; and when the paroxysms were violent, the muscles of the abdomen were contracted spasmodically.

A most frequent symptom was pain in the loins, about the situation of the lumbar fascia; also in the deltoid muscles. The patients were chilly, with great languor and lassitude; the eutaneous secretion was diminished; the intellect was clear, but there was generally depression of the nervous, sanguiferous, and muscular systems; the pulse was low and feeble; the features were sallow and shrunk; and the muscles were soft and flabby. The fluid vomited was often mixed with bile, and occasionally coffee-ground secretion; the freces were dark, and highly offensive, with scybala; the secretion from the kidneys was scanty, and of a dark-red colour, almost ike porter.

Treatment.-The bowels were in general so obstinately costive, that large and frequently-repeated doses of the strongest cathartics were often necessary Sometimes I began with a large dose of calomel, followed by sulphate of magnesia or castor oil. When these did not produce sufficient effect, croton oil and voluminous enemata were used with manifest advantage. Croton-oil frictions were useful when vomiting was excessive; to allay the sickness, hydrocyanic acid, or small doses of calomel-and-opium. By the omission of the daily purgative the symptoms would in many cases return. The patients were directed to take light, nutritious food, and milk, during convalescence. Some cases were so slight (althongh the gums:wore blue) that the patients would not take medicine.

In violent cases, when other remedies had failed, the warm bath relaxed the spasms very speedily. Opiate frictions and bran poiltices were useful in -milder cases. The soothing effects of the warm bath in some instances were quite astonishing, and in violent cases it should never be omitted, for it not only relieves the abdominal pain, but allays the spasms and irritation in other muscles of the body. When there was tenderness in the abdomen on pressure, leeches were beneficial, and in one case venesection was absolutely necessary.

A young woman, Phoebe W-, aged twenty-two, who had suffered severely from peritonitis three years before, had been ill from the effects of lead (with very blue gums) more than a week, when the pain in the abdomen much increased, with great tenderness on pressure, feverish excitement, and rapid pulse. Venesection and leeches were used, and the-sufferings were mitigated; the symptoms returned with increased violence, and bleeding and other antiphlogistic remedies were repeated. The blood was buffed and cupped. As the inflammatory symptoms subsided she beeame-almost maniacally hysterical on several successive nights, and yet she recovered many weeks sooner than any of the family, so that $I$ am inclined to believe that in strong subjects venesection may be useful.

In very severe cases there was great exhaustion, and a slight leaden hue in the countenance; then stimulants became absolutely necessary.

It was melancholy to observe ten or twelve patients in poor families, all suffering at the same time, and scarcely able to assist each other, without funds, and without necessaries.

In one of the last numbers of the Provincial Journal I found iodide of potass, recommended in small doses, as a remedy for the poisonous effects of lead and mercury, by forming a soluble salt, which is readily eliminated. The experiments were performed by M. Natalis Guillot, read before the Académie des Sciences, Paris. I have tried this remedy in some cases, and certainly, gums that had been blue for months in a fow days changed to a more natural appearance, and no symptoms of severity have since occurred; in fact, the patients appear now quite convalescent.

The poison of lead appears to exert its deleterious effects mostly on the muscular system. One of the most frequent symptoms was an acute or chronic pain in the muscles of the loins, and perhaps in the fascia lumborum; and in many cases the larger muscles of the body were affected with pain. Probably the abdominal pain is occasioned by the spasmodic constriction of the muscular fibres of the larger bowels, thus diminishing their contractility of tissue; and this may, in part, be the cause of constipation, though in some cases the spasm may be confined to the abdominal muscles.

In a youth eighteen years of age, with blue gums, the pains were confined to the muscles of the arms and legs, and he suffered most severely from violent contraction in all the extremities, without pain of abdomen or loins.

In this neighbourhood we have numerous glass-houses, and many hundreds of men are constantly employed in the fumes of lead, whom we know by a sallow, thin, unhealthy aspect, with soft and flabby muscles. The relapses in some constitutions were very frequent and very severe, sometimes after several weeks had elapsed, and patients thought themselves well.

Mr. S _ aged forty-seven, an irritable man of nervous temperament, had suffered from several severe paroxysms; the pains begun gradually to return a month after the onset of the disease, and increased like the pains of labour, every ten minutes, or a quarter of an hour; there was great difficulty in relieving his bowels, (which, in many instances, were locked up for a week or nine days.) When the bowels were cleared, large and repeated doses of laudanum only mitigated his sufferings, till at length, at the end of thirty-six hours, the pains 